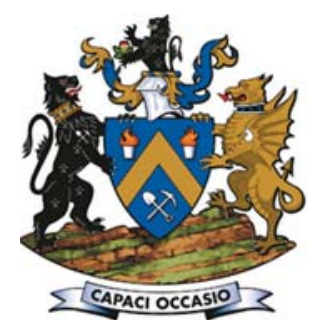

\title{
Understanding aqueous-in-organic entrainment in copper solvent extraction
}

\author{
by P. Cole*, T. Bednarski*, L. Thomas*, D. Muteba*, \\ G. Banza*, and M. Soderstrom*
}

\section{Synopsis}

In copper solvent extraction, aqueous-in-organic entrainment results in the carry-over of unwanted species into the electrowinning process with negative cost implications. The need to bleed is increased and the purity of the copper cathode is potentially compromised, depending on the impurities being transferred $\left(\mathrm{Cl}, \mathrm{NO}_{3}, \mathrm{Fe}, \mathrm{Mn}\right)$. In some cases, entrainment results in elevated levels of manganese in the electrolyte which can cause oxidative conditions to develop and degradation of the organic phase. Degraded organic phase detrimentally affects the physical performance of the copper solvent extraction process, contributing to even higher aqueous-in-organic entrainment. Aqueous entrainment may be minimized through good operating practices and maintenance of the organic quality, but the accurate measurement of entrainment remains a challenge. This paper presents coalescing devices designed to provide more exact measurements of aqueous-in-organic entrainment.

\section{Keywords}

copper solvent extraction, aqueous entrainment, measurement techniques, minimization. mass balances can be used to estimate aqueous entrainments and are helpful as a tool to troubleshoot operations with a view to improving plant performance.

\section{Coalescence and entrainment}

The dispersion of two phases on mixing and the rate at which the dispersed phases disengage (coalescence) are integral steps in the SX process that govern the design and operation of a plant. Since the entrainment of one phase in another is essentially the result of retarded coalescence, a closer look at the coalescence of an organic-continuous mixture (aqueous droplets dispersed in an organic matrix) should assist in understanding of Ain- 0 entrainment. In the coalescence of aqueous droplets dispersed in an organic continuous phase, drop-interface and dropdrop coalescence are believed to proceed through a number of discrete stages, with the rate-limiting steps said to be the formation and drainage of the film of the continuous phase at the interface. Any factor that retards the formation and drainage of the interfacial film will influence the rate of coalescence and, by implication, aqueous entrainment (Ritcey, 2006).

\section{Aqueous entrainment in copper SX operations}

Both operational and chemical factors influence aqueous entrainment in copper SX operations. Probably the most important entrainment to minimize in operations is the aqueous entrained in the loaded organic (LO)
* Cytec Solvay Group, Brussels, Belgium.

(C) The Southern African Institute of Mining and Metallurgy, 2016. ISSN 2225-6253. This paper was first presented at the, Copper Cobalt Africa Conference, 6-8 July 2015, Avani Victoria Falls Hotel, Victoria Falls, Livingstone, Zambia. 


\section{Understanding aqueous-in-organic entrainment in copper solvent extraction}

phase that exits the E1 extraction stage because this solution, whether pre-settled in a LO tank or passing via a wash stage, will cause carry-over of undesired impurities from the pregnant leach solution (PLS) into the EW circuit.

\section{Operating factors that influence aqueous entrainment}

A number of factors related to the design of SX equipment are specifically focused on minimizing A-in-O entrainment. These include the following:

> LO tank designs that assist in the removal of A-in-O entrainment

> Coalescer devices such as the Chuquicamata LO coalescer and pace settlers

> Settler internals and picket fences directed at lowering aqueous entrainment.

In addition to settler and tank modifications, plants can also make changes to mixing equipment to achieve a more uniform droplet size and assist coalescence by a focus on low-shear and reduced mixing intensity.

\section{Phase continuity}

The preferred mode of continuity for a mixer-settler where LO exits the extraction circuit is aqueous continuity because coalescence from an organic-continuous dispersion will tend to leave aqueous droplets in the settled organic phase (Sole, 2008). However, in many operations, particularly in Africa where agitation leaching is common, the total suspended solids (TSS) content of the SX circuit is often high and stable operation is possible only in organic-continuous mode, which makes crud more compacted and stabilized at the interface, depending on the hydrophobicity of the crud solids. Managing crud in these plants is such a problem that organic-continuous operation is often mandatory, even at the expense of increased entrainment (Sole, 2008). Another reason for operating in organic-continuous mode is if dissolved silica is present in the PLS. If the levels of colloidal silica are high enough, a stable emulsion forms with aqueous-continuous mixing that fails to separate in the settler and can necessitate a shutdown of the SX plant.

\section{Specific settler flux and organic bed depth}

An important parameter in the design of gravity settlers is the specific settler flux, which is a function of the total flow rate of solution that enters a settler and defines the design settling area. Entrainment can be high in copper SX plants if operating specific settler fluxes are over the accepted range of 4 to $8 \mathrm{~m}^{3} / \mathrm{m}^{2} / \mathrm{h}$ (Robinson et al., 2008).

In the E1 mixer-settler units, the height of the organic phase in the settler is important to ensure low aqueous entrainment, especially for organic continuity where the aqueous is the dispersed phase. Because of the cost associated with the organic inventory, there is often a tendency to reduce the organic height in settlers. There is some debate on what is an optimum phase velocity or difference between the phases, but phase velocity has a clear impact on entrainment by affecting the amount of time available for the droplets to coalesce within the settler. Dependent on bed height and flow rate, the linear velocity (LV) for each phase is defined as:

$$
\mathrm{LV}_{\text {ORGANIC }}=Q_{\mathrm{O}} / W \cdot \mathrm{H}_{\mathrm{O}} \text { and } \mathrm{LV}_{\text {AQUEOUS }}=Q_{\mathrm{A}} / W \cdot \mathrm{H}_{\mathrm{A}}
$$

where $Q$ is the volumetric flow rate, $W$ the settler width, $H$ the height of the phase in the settler, and subscripts $\mathrm{O}$ and $\mathrm{A}$ refer to organic and aqueous phases respectively. Table I shows the diverging phase linear velocities for reduced organic heights in a settler.

Organic linear velocities typically fall in the range 100 to $200 \mathrm{~m} / \mathrm{h}(3$ to $6 \mathrm{~cm} / \mathrm{s})$ and it is generally recommended that an organic bed height of 25 to $35 \mathrm{~cm}$ be maintained (Sole, 2008). To put this into the context of a full-scale settler, $32 \mathrm{~m}$ wide and with an aqueous flow rate of $1000 \mathrm{~m}^{3} / \mathrm{h}$, the organic linear velocity for an organic height of $20 \mathrm{~cm}$ is $312 \mathrm{~m} / \mathrm{h}$, which is substantially higher than the typical accepted velocities. At $312 \mathrm{~m} / \mathrm{h}$ and a settler length of $20 \mathrm{~m}$, the organic takes 3.85 minutes to reach the overflow weir and, if the velocity is $200 \mathrm{~m} / \mathrm{h}$, the time to the weir is doubled to 6 minutes. It is not unreasonable to expect a substantial drop in aqueous entrainment simply by increasing the organic bed depth by $10 \mathrm{~cm}$.

\section{Chemical factors that influence aqueous entrainment}

It is now accepted in the industry that the composition of the organic phase, per se, has little influence on the coalescing behaviour of dispersions. It is factors such as temperature and amount and type of solids present that result in crud formation and densities and viscosities of both the aqueous and organic phases that can significantly influence coalescence and aqueous and organic entrainment (Soto, 2012).

\section{Organic quality}

Organic quality can have a significant impact on the amount of A-in-O entrainment that is experienced at an operation (despite the steps taken to minimize the issue). Over time, the organic inventory accumulates contaminants from the PLS, electrolyte, or organic that are recovered and returned to the circuit from ponds and the EW circuit (Hutzler et al., 2015). These contaminants can be interfacially active species and are indicated by a decrease in interfacial tension (IFT). The addition of surface-active components is found to generally retard coalescence as they accumulate at the interface and surface of droplets, resulting in a reduction in film drainage time. They are therefore a cause of increase in aqueous entrainment (Ritcey, 2006). Effective clay treatment with the correct dosage of acid-activated bentonite clay recovers the organic quality by removing the surface-active components (Hutzler et al., 2015).

\section{Side-by-side pilot plant trials}

The results of side-by-side pilot plant trials conducted at two copper SX operations demonstrate the effect of organic quality on aqueous entrainment. In these trials, plant organic

\section{Table I}

Variation of linear velocity for solution bed depths in a gravity settler (internal O/A flow ratio of 2)

\begin{tabular}{|l|c|c|c|}
\hline Height of organic $(\mathbf{m})$ & $\mathbf{0 . 4}$ & $\mathbf{0 . 3}$ & $\mathbf{0 . 2}$ \\
\hline LV $_{\text {ORGANIC }}$ & $\begin{array}{c}5 Q_{A} / W \\
1.7 Q_{A} / W\end{array}$ & $\begin{array}{c}6.7 Q_{A} / W \\
1.4 Q_{A} / W\end{array}$ & $\begin{array}{c}10 Q_{A} / W \\
\text { LV }\end{array} Q_{A} / W$ \\
\hline
\end{tabular}




\section{Understanding aqueous-in-organic entrainment in copper solvent extraction}

is compared with plant organic after clay treatment at a mass fraction of $5 \%$ clay. The operating parameters for the trials are given in Table II. All stages were operated in organiccontinuous mode. The trials differed in both scale and duration of operation.

For Trial 1, entrained PLS in the loaded organic from stage E1 was periodically drained from the bottom of the two loaded organic drums. Entrainment was calculated by dividing the drained aqueous volume by the total volume of organic that had entered the loaded organic drum over the time period. The results given in Table III show that clay treatment significantly reduced the A-in-O entrainment by between $32 \%$ and $56 \%$ during normal operation. The time periods are for different days of operation.

For Trial 2, the A-in-O entrained in the loaded organic was accumulated in a coalescing device over the period of the trial. Figure 1 shows that the plant with untreated organic accumulated $65 \%$ more entrained aqueous than the plant with treated organic.

\section{The cost of carry-over of species into electrolyte}

\section{Electrolyte bleed}

Aqueous entrainment is the cause of impurity transfer of species like $\mathrm{Cl}, \mathrm{NO}_{3}$, and $\mathrm{Mn}$ into the electrolyte, while $\mathrm{Fe}$ transfer is due to a combination of entrainment and chemical extraction. Maintaining particular concentrations of species in the electrolyte is achieved principally through a bleed of the lean electrolyte (LE). Costs associated with the bleed are due to the following factors (discussed further in a later section):

> Loss of EW reagents, such as acid, cobalt, levelling aids, and mist suppressant from the electrolyte

> Re-extraction of copper

$>$ Copper lost to the raffinate.

Table II

Operating parameters for side-by-side trials comparing untreated and clay-treated plant organic

\begin{tabular}{|l|c|c|} 
& Trial 1 & Trial 2 \\
\hline Circuit configuration & $1 \mathrm{E}+1 \mathrm{~S}$ & $2 \mathrm{E}+2 \mathrm{~S}+1 \mathrm{~W}$ \\
Mixer volume & $40 \mathrm{~L}$ & $700 \mathrm{~mL}$ \\
Duration of operation & $13 \mathrm{~d}$ & $40 \mathrm{~h}$ \\
$\Delta \mathrm{IFT}$ (clay treated - untreated) & $6.5 \mathrm{dyne} / \mathrm{cm}$ & $2.5 \mathrm{dyne} / \mathrm{cm}$ \\
PLS flow rate & $3-4 \mathrm{~L} / \mathrm{min}$ & $0.1 \mathrm{~L} / \mathrm{min}$ \\
Organic flow rate & $8-9 \mathrm{~L} / \mathrm{min}$ & $0.1 \mathrm{~L} / \mathrm{min}$ \\
\hline
\end{tabular}

\section{Table III}

Trial 1 - aqueous entrainment from E1 stage for side-by-side pilot trial

\begin{tabular}{|l|c|c|c|}
\hline \multirow{2}{*}{ Time period } & \multicolumn{2}{|c|}{ A-in-O entrainment $\left(\mathrm{mL} / \mathrm{m}^{3}\right)$} & \multirow{2}{*}{ Decrease (\%) } \\
\cline { 2 - 3 } & Untreated & Treated & \\
\hline Period 1 & 2373 & 1038 & 56.2 \\
Period 2 & 1963 & 1287 & 34.4 \\
Period 3 & 1469 & 988 & 32.8 \\
\hline
\end{tabular}

The quantity of bleed is dependent on the extent of contamination of the electrolyte, and the associated costs can be significant. For plants that are pushing copper production levels - common in the African operations - there is a resistance to bleeding electrolyte from the EW circuit, but such a practice has to be carefully managed to ensure good plant performance is maintained.

\section{Deleterious effects of species build-up in electrolyte}

Besides the need to bleed electrolyte, there are other possible consequences, listed in Table IV, of carry-over of chemical species from the PLS to the electrolyte. These consequences have associated costs, although they are primarily indirect in nature.

\section{Chloride}

Chloride entrainment is a concern at a number of operations, especially in Chile where elevated $\mathrm{Cl}$ levels in the PLS are not uncommon, originating from the chloride-containing atacamite ore and chloride-containing process water. Despite chloride concentrations as high as $50 \mathrm{~g} / \mathrm{L}$ in the PLS of Latin American operations, chloride levels in the electrolyte are maintained at around 30 to $45 \mathrm{mg} / \mathrm{L}$ through a combination of wash stages, electrolyte bleed, and $\mathrm{Cl}_{2}$ gas evolution in the tankhouse.

\section{Nitrate}

Nitrate is occasionally a cause for a bleed but this is largely limited to operations in the north of Chile. Some of the Latin

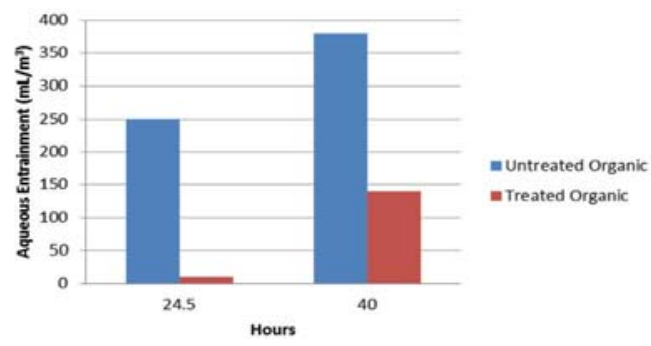

Figure 1-Trial 2 - aqueous entrainment accumulated from loaded organic for side-by-side pilot trial

\begin{tabular}{|c|c|}
\hline \multicolumn{2}{|c|}{$\begin{array}{l}\text { Table IV } \\
\text { Consequences of carry-over of chemical species } \\
\text { into the electrolyte }\end{array}$} \\
\hline $\begin{array}{l}\text { Chemical } \\
\text { species transferred }\end{array}$ & Possible consequence \\
\hline $\mathrm{Cl}$ & $\begin{array}{l}\text { - Downgrade in cathode quality } \\
\cdot \mathrm{Cl}_{2} \text { gas generation in tankhouse } \\
\text { - Corrosion of anode and pitting of cathodes }\end{array}$ \\
\hline $\mathrm{NO}_{3}$ & $\begin{array}{l}\text { Nitration of organic phase and increased } \\
\text { anode corrosion }\end{array}$ \\
\hline $\mathrm{Mn}$ & $\begin{array}{l}\text { - Oxidative degradation of organic } \\
\text { - Precipitation of amorphous } \mathrm{MnO}_{2} \text { in } \\
\text { electrolyte } \\
\text { - Increased corrosion of anodes } \\
\text { - } \mathrm{Cl}_{2} \text { gas generation in tankhouse (promoted) } \\
\text { - Occlusion of } \mathrm{Pb} \text { in cathode }\end{array}$ \\
\hline $\mathrm{Fe}$ & - Decrease in EW current efficiency \\
\hline
\end{tabular}




\section{Understanding aqueous-in-organic entrainment in copper solvent extraction}

American operations experience relatively high $\mathrm{NO}_{3}$ levels in the plant PLS, the worst case reported being the Lomas Bayas plant (Zambra et al., 2013). Transfer of nitrate from the PLS to the higher acid-containing LE can lead to operational problems. At specific conditions, nitration of the oxime in the plant organic occurs, resulting in decreased copper recoveries, and deteriorating phase separation efficiencies and $\mathrm{Cu}: \mathrm{Fe}$ selectivity. In extreme cases, entrainment of high $\mathrm{NO}_{3}$ PLS has impacted plant operability.

\section{Manganese}

Issues with manganese in the tankhouse have been reported in a number of regions, such as Australia, North America, and Latin America (Miller, 1995) and are a concern for many African operations. Elevated levels of manganese in the electrolyte are due to high concentrations of manganese in the PLS from the leaching of the manganese-containing cobalt mineral heterogenite and high aqueous entrainment. Under oxidative conditions, the manganese transferred into the EW circuit can result in the generation of higher oxidation state manganese species (up to $\mathrm{Mn}^{7+}$ ), which when contacted with the organic phase cause degradation to occur (Bednarski, 2008; Bednarski et al., 2011). Maintaining a $\mathrm{Fe}^{2+} / \mathrm{Mn}$ ratio of at least 5 in the electrolyte is said to ensure that oxidizing conditions do not develop (Bednarski et al., 2011). Miller (1995) reports that maintaining a $\mathrm{Fe}_{\text {total }} / \mathrm{Mn}$ $\left(\mathrm{Fe}_{\text {total }}=\mathrm{Fe}^{3+}+\mathrm{Fe}^{2+}\right.$ or total $\left.\mathrm{Fe}\right)$ ratio of around 8 to 10 in the electrolyte prevents oxidative conditions from developing. However, there are plants in the African Copperbelt that operate the EW circuit with Fe/Mn ratios as low as 1 without developing oxidative conditions. Cobalt, which is also carried over into the electrolyte, is suspected to be the mitigating factor inhibiting the development of oxidative conditions (Miller, 2011). However, African operations are always at risk of developing oxidative conditions during start-up when the Fe and Co levels are still building up in the electrolyte. Monitoring the oxidation-reduction potential (ORP) of the electrolyte is the best way to ensure that oxidizing conditions are absent.

Oxidation of the oxime results in lower copper transfer. Oxidative degradation of the organic phase causes the formation of surface-active components that build up in the organic phase, affecting the IFT properties and resulting in an increase in phase separation times and entrainment, a decrease in kinetics that negatively impacts stage efficiencies, and a decrease in $\mathrm{Cu}$ :Fe selectivity (Bednarski et al., 2011; Soderstrom et al., 2010). Treatment of organic with acidactivated bentonite at the correct clay dosages recovers the quality and the performance properties of the plant organic.

\section{Iron}

Iron contamination of the electrolyte, both from chemical and physical transfer, is the most common factor requiring an electrolyte bleed. Elevated iron levels in the electrolyte reduce current efficiency, thereby increasing the power cost per unit of electrowon copper (Bednarski, 2008). Some African copper plants that have reduced or even eliminated electrolyte bleed to push production exhibit current efficiencies as low as $62 \%$. It should be noted, however, that many other operational factors in the EW process, besides elevated iron levels, reduce current efficiency. These can be addressed by instituting judicious maintenance practices in the EW circuit.

\section{Measuring aqueous entrainment \\ 'Grab sample' method}

It is generally difficult to obtain an accurate measurement of aqueous entrainment from a large continuous flow like an organic phase. Most commonly used in the industry, the 'grab sample' method typically consists of taking $100 \mathrm{~mL}$ samples from the organic overflow launder into an oil-inwater emulsion bottle and spinning them in a centrifuge (Figure 2). The method is highly dependent on the point of sample collection, reproducibility is extremely userdependent, and accuracy requires the measurement of multiple samples. In addition, the volumes of entrained aqueous are extremely small, which can make measurements in a small container meaningless; $1000 \mathrm{~mL} / \mathrm{m}^{3}$, for example, is a mere $0.1 \mathrm{~mL}$ in the flask shown in Figure 2. Due to the deficiencies in the current methodology, in many plants A-in$\mathrm{O}$ entrainment measurements are simply not recorded or recorded very infrequently.

\section{Continuous measurement methods}

Methods based on continuous measurement remove some of the variability in the sampling method and provide more representative data. They also collect larger samples, allowing for more meaningful entrainment measurements. The following section describes two relatively simple measurement techniques that have been used in commercial operations to assist in establishing a baseline measurement.

\section{Equipment}

Two continuously operated coalescing devices to provide more accurate aqueous entrainment measurements at copper SX plants are shown in Figure 3. One is a column design and the other is based on a mixer-settler design for conducting on-site continuous countercurrent pilot plant trials.

Figure $3 \mathrm{a}$ depicts the column coalescer. It is designed to coalesce entrained aqueous onto the packing from the organic exiting a mixer-settler unit (the overflow launder). Over time, the droplets of aqueous become large enough to settle into the aqueous collection pipe at the base of the coalescer. Based on this phenomenon, the unit will establish an equilibrium where the rate of coalescence onto the packing material matches the rate of settled aqueous such that measurements of the A-in-O entrainment can be made.

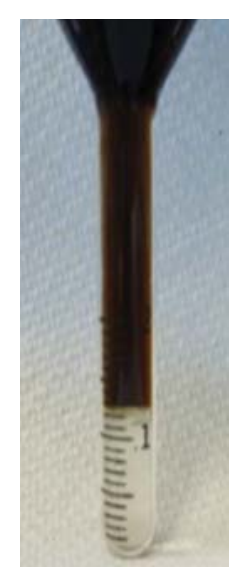

Figure 2-Centrifuge sample holder showing separated aqueous phase 


\section{Understanding aqueous-in-organic entrainment in copper solvent extraction}

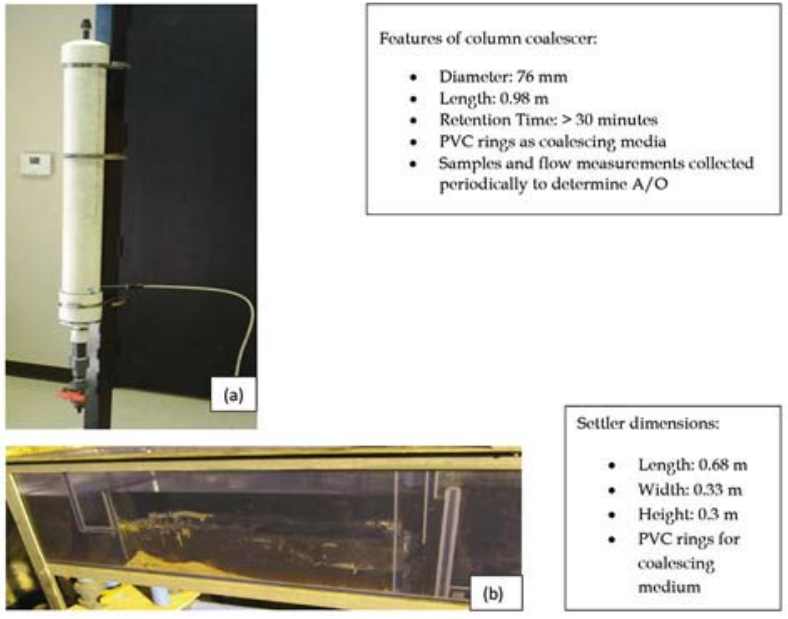

Figure 3-(a) Column and (b) settler-type coalescing device used for improved aqueous entrainment measurement

The coalescer should be placed in a location close to the organic advance line on the SX settler organic launder where samples for A-in-O entrainment measurements are taken. Sampling in the organic advance line will ensure the feed to coalescer is indicative of the entrainment across the length of the weir. An appropriately sized pump is used to meter organic into the column via the small-diameter pipe shown near the bottom of the column. Organic exits at the top of the column directly into the settler organic launder.

Figure $3 \mathrm{~b}$ depicts the mixer-settler device. The coalescing chamber is filled with the polyvinyl chloride (PVC) coalescing media before use to measure the A-in-O entrainment. The device is placed adjacent to the overflow launder where LO exits the E1 settler. An appropriately sized metering pump is used to deliver LO from the launder into the settling chamber. Organic is pumped at a set flow rate over a 12-hour measurement period and exits directly into the organic overflow launder. The coalesced aqueous is drained from the bottom of the settling chamber to calculate an entrainment value.

\section{Results}

Figure 4 shows actual A-in-0 entrainment levels measured in the loaded organic exiting the extraction circuit in a copper SX operation in Africa. Two observations appear from this data: (1) entrainment levels are relatively high, and (2) they are extremely variable.

In Figure 4, the graph on the left plots daily aqueous entrainment values collected over a one-month period. It shows values as low as $2341 \mathrm{~mL} / \mathrm{m}^{3}$ and as high as $11389 \mathrm{~mL} / \mathrm{m}^{3}$, with an average value of $4176 \mathrm{~mL} / \mathrm{m}^{3}$ and standard deviation of $1960 \mathrm{~mL} / \mathrm{m}^{3}$. The histogram on the right indicates that $83 \%$ of the time, the measured aqueous entrainment was between 2000 and $5000 \mathrm{~mL} / \mathrm{m}^{3}$.

The collection of this data assisted the operation in better recognizing the operational parameters that resulted in higher A-in-O entrainment from the LO stage to the LO tank. In particular, it re-emphasized the importance of operating the decant pump to capture the majority of the aqueous in the LO tank and return it to the extract circuit before contamination of the electrolyte occurred. The use of the coalescer allowed the operation to have a real-time measurement of aqueous entrainment and to better evaluate the impact of operational changes on the physical transfer. Among the operational changes that were considered, some of which were implemented, were modifications of the organic bed depth, organic quality, O/A ratio, and a picket-fence arrangement within the settler.

\section{Using mass balances to calculate electrolyte bleed and costs}

Once the average entrainment has been estimated, it is possible to validate these measurements utilizing mass balances. The mass balance also allows the operation to assess the bleed requirements and cost associated with the bleed. This assists the operation in prioritizing its efforts in addressing entrainment relative to other operational priorities. The mass balance stream flows are shown in Figure 5 for the EW tankhouse (TH).

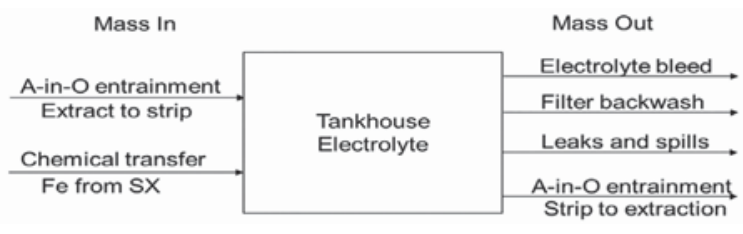

Figure 5-Mass balance streams for tankhouse electrolyte
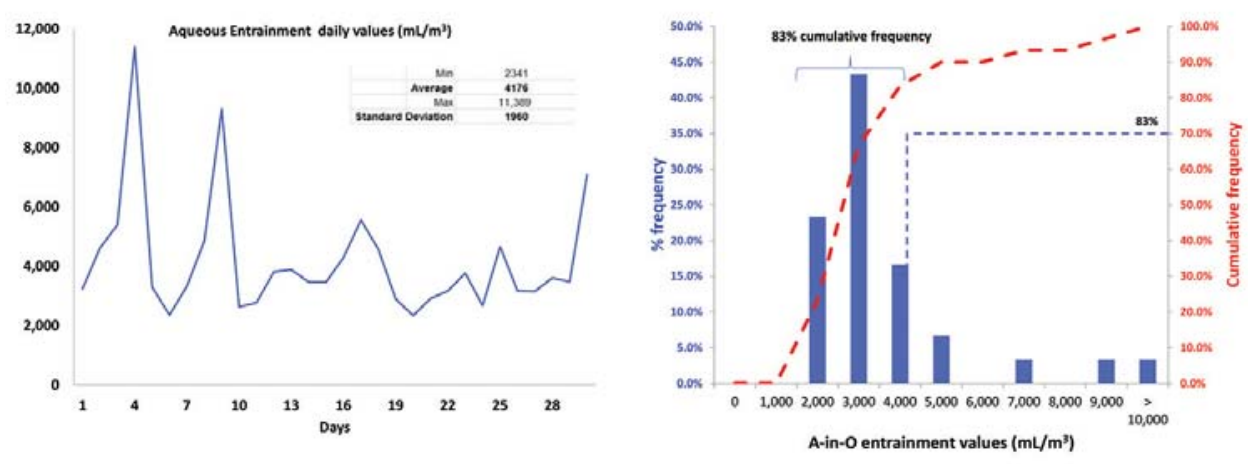

Figure 4-A-in-O measurements from an E1 settler organic launder 


\section{Understanding aqueous-in-organic entrainment in copper solvent extraction}

The mass balance calculation for one set of conditions, assuming an A-in-O in the $\mathrm{LO}$ of $4000 \mathrm{~mL} / \mathrm{m}^{3}$ and an A-in-O entrainment of $1000 \mathrm{~mL} / \mathrm{m}^{3}$ in the barren organic (BO), is shown in Table $\mathrm{V}$.

As shown, the mass of impurities into the electrolyte exceeds the mass of impurities that would be lost due to 'natural' losses (A-in-O entrainment from strip to extract and filter backwash). Under these conditions, an additional intentional bleed would be required. Assuming the tankhouse impurity concentrations were allowed to reach the maximum target ( $3 \mathrm{~g} / \mathrm{L} \mathrm{Fe}$ and $0.3 \mathrm{~g} / \mathrm{L} \mathrm{Mn}$ ), the amount of bleed required for each element X is: (Mass X in - Mass X out) / TH target LE X, which gives the values shown in Table VI.

The actual bleed would be based on the highest value. In this case, the plant would bleed for Fe at a flow rate of $10.05 \mathrm{~m}^{3} / \mathrm{h}$. Based on an electrolyte composition of $35 \mathrm{~g} / \mathrm{L} \mathrm{Cu}$ and $190 \mathrm{~g} / \mathrm{L} \mathrm{H}_{2} \mathrm{SO}_{4}$, this would resut in the losses of copper and acid from the tankhouse summarized in Table VII.

Other than returning copper and acid back to the leaching circuit (the copper needing to be re-extracted), the bleed results in the loss of the other tankhouse reagents, such as cobalt sulphate, mist suppressant, and levelling aids. A cost breakdown associated with the bleed of $10.05 \mathrm{~m}^{3} / \mathrm{h}$ is given in Table VIII.

Electrolyte bleed requirements for various aqueous entrainment values are shown in Table IX. The cost of the bleed ranges from US\$58.7 to US\$86 8 per ton $\mathrm{Cu}$ recovered. As would be expected, any increase in A-in-O entrainment will have a significant impact on the bleed required. As shown, under these conditions (maintaining constant chemical iron transfer and constant A-in-O entrainment from strip), a change in the A-in-O entrainment from extract affects which element the plant would need to bleed to control. At an excessive A-in-O entrainment of $8000 \mathrm{~mL} / \mathrm{m}^{3}$, the plant would need to begin bleeding to maintain $\mathrm{Mn}$ instead of Fe.

Note: These entrainment values are considered very high - but are not unheard of in operations where operational controls to minimize entrainment are not implemented.

Table $\mathrm{V}$

\section{Mass balance around tankhouse to determine electrolyte bleed requirement}

\begin{tabular}{|l|c|c|l|c|c|}
\hline \multicolumn{2}{|c|}{ Mass in } & \multicolumn{3}{c|}{ Mass out (natural) } \\
\hline Organic flow & $\mathrm{m}^{3} / \mathrm{h}$ & 1300 & LE flow & $\mathrm{m}^{3} / \mathrm{h}$ & 750 \\
A-in-O entrainment extract & $\mathrm{mL} / \mathrm{m}^{3}$ & 4000 & Filter backwash & $\mathrm{m}^{3} / \mathrm{h}$ & 0.11 \\
PLS Fe & $\mathrm{g} / \mathrm{L}$ & 1.23 & A-in-O in BO & $\mathrm{mL} / \mathrm{m}^{3}$ & 1000 \\
PS Mn & $\mathrm{g} / \mathrm{L}$ & 0.45 & LE Fe & $\mathrm{g} / \mathrm{L}$ & 1.5 \\
Fe from chemical transfer & $\mathrm{mg} / \mathrm{L}$ & 20 & LE Mn & $\mathrm{g} / \mathrm{L}$ & 0.30 \\
\hline TH target LE Fe (max.) & $\mathrm{g} / \mathrm{L}$ & 3.0 & & & \\
TH target LE Mn (max.) & $\mathrm{g} / \mathrm{L}$ & 0.30 & & & \\
\hline Mass Mn in entrainment & $\mathrm{kg} / \mathrm{h}$ & 2.34 & Mass Mn out & $\mathrm{kg} / \mathrm{h}$ & 0.23 \\
Mass Fe in entrainment & $\mathrm{kg} / \mathrm{h}$ & 6.40 & & & \\
Mass Fe in transfer & $\mathrm{kg} / \mathrm{h}$ & 26.00 & & & \\
Total Fe in & $\mathrm{kg} / \mathrm{h}$ & 32.40 & Mass Fe out & $\mathrm{kg} / \mathrm{h}$ & 2.25 \\
\hline
\end{tabular}

\begin{tabular}{|l|l|}
\hline \multicolumn{2}{|l|}{ Table $\mathrm{VI}$} \\
Calculated tank house bleed $\left(\mathbf{m}^{\mathbf{3}} \mathbf{h}\right)$ \\
\hline Bleed for $\mathrm{Fe}$ & 10.05 \\
Bleed for $\mathrm{Mn}$ & 7.05 \\
\hline
\end{tabular}

Table VII

Copper and acid loss associated with a $10.05 \mathrm{~m}^{3} / \mathrm{h}$ bleed from the tankhouse

\begin{tabular}{l|c|c}
\hline LE Cu concentration & $\mathrm{g} / \mathrm{L}$ & 35 \\
$\mathrm{LE} \mathrm{H} \mathrm{H}_{2} \mathrm{SO}_{4}$ concencentration & $\mathrm{g} / \mathrm{L}$ & 190 \\
$\mathrm{Cu}$ from tankhouse & $\mathrm{kg} / \mathrm{d}$ & 8441 \\
Acid from tankhouse & $\mathrm{kg} / \mathrm{d}$ & 45822 \\
\hline
\end{tabular}

Table VIII

Cost breakdown of electrolyte bleed $\left(10.05 \mathrm{~m}^{3} / \mathrm{h}\right)$ (assumptions: $6 \%$ of $\mathrm{Cu}$ lost, $94 \%$ of $\mathrm{Cu}$ reextracted, reagent cost approx. $10 \%$ of total)

\begin{tabular}{|l|c|c|c|}
\hline & t/a & US\$/t & US\$/a \\
\hline Acid & 16725 & 250 & 4181250 \\
Cu lost & 185 & 6000 & 1109149 \\
Cu re-extracted & 2896 & 18 & 52130 \\
Reagents & & & 530000 \\
\hline Total (\$ per annum) & & 5872529 \\
\hline
\end{tabular}

Table IX

Electrolyte bleed requirements for various LO A-in0 entrainment values

\begin{tabular}{|l|c|c|c|l|}
\hline A-in-O in LO & $\mathrm{mL} / \mathrm{m}^{3}$ & 4000 & 6000 & 8000 \\
Bleed for Fe & $\mathrm{m}^{3} / \mathrm{h}$ & 10.05 & 11.11 & 12.11 \\
Bleed for $\mathrm{Mn}$ & $\mathrm{m} 3 / \mathrm{h}$ & 7.05 & 10.95 & 14.85 .25 \\
\hline
\end{tabular}

\section{Conclusions}

A-in-O entrainment is an important parameter in SX operations, but is rarely measured accurately. Although plants allocate capital to minimize aqueous entrainment, there are also a number of operational adjustments that can be made, including organic quality adjustments, that can minimize entrainment costs. However, identifying the right parameters to optimize requires proper sampling and measurement procedures, which can be facilitated by relatively simple continuous measurement devices. In addition, operating copper SX plants should validate A-in-O measurements by conducting mass balances.

\section{References}

BEDNARSKI, T. 2008. Behavior of iron and manganese in electrowinning solutions - a Hull cell study. Tucson SME, December 2008. Cytec Industries Inc.

Bednarski, T., Soderstrom, M., and WigGetT, S. 2011. Oxidation in copper SX processes. Proceedings of the ALTA 2011 Copper-Nickel-Cobalt Conference. ALTA Metallurgical Services, Melbourne, Australia. 9 pp. 


\section{Understanding aqueous-in-organic entrainment in copper solvent extraction}

Hutzler, B., Cole, P., Thomas, L., Bednarski, T., and Zambra, R. 2015. Clay treatment improvements using ACORGA® CB1000 clay binder. Proceedings of Copper Cobalt Africa: in Association with the 8th Southern African Base Metal Conference, Victoria Falls, Zambia, 6-8 July 2015. Southern African Institute of Mining and Metallurgy, Johannesburg.

MiLLER, G. 1995. The problems of manganese and its effects on copper SX-EW operations. Proceedings of Copper 95-Cobre 95: Vol. 3. Electrorefining and Hydrometallurgy of Copper. Cooper, W.C. (ed.). Canadian Institute of Mining, Metallurgy and Petroleum, Montreal, Canada. pp. 649-663.

MiLLER, G. 2010. Methods of managing manganese effects on copper SX-EW plants. Proceedings of the ALTA 2010 Nickel Cobalt Copper Conference. ALTA Metallurgical Services, Melbourne, Australia.

RITcey, G.M. 2006. Solvent Extraction: Principles and Applications to Process Metallurgy. Chapter 5: Dispersion and Coalescence. Book 1, revised edition. Gordon Ritcey \& Associates, Ottawa. pp. 208-228.

Robinson, T., Moats, M., Davenport, W., Karcas, G., Demetrio S., and Domic, E. 2008. Copper solvent extraction - 2007 world operating data. Proceedings of ISEC 2008. Volume I. Moyer, B.A. (ed.). Canadian Institute of Mining, Metallurgy and Petroleum, Montreal, Canada. pp. 435-440.

Soderstrom, M., Bednarski, T., and Villegas, E. 2010. Stage efficiency in copper solvent extraction plants. Proceedings of the SME Annual Meeting, Phoenix, AZ, February 2010. Society for Mining, Metallurgy \& Exploration, Littleton, CO. Preprint 10-106.

SoLE, K.C. 2008. Solvent extraction in the hydrometallurgical processing and purification of metals: process design and selected applications. Solvent Extraction and Liquid Membranes: Fundamentals and Applications in New Materials. Aguilar, M. and Cortina, J.L. (eds.). Taylor \& Francis, Boca Raton, FL. pp. 141-200

Soто, A. 2012. The impact of PLS viscosity on solvent extraction. Cytec Solutions - For Solvent Extraction, Mineral Processing and Alumina Processing, vol. 16, Cytec Industries Inc., USA.

Zambra, R., QUiladran, A., and CASTRo, 0. 2013. The phenomenon of nitration in the Chilean copper hydrometallurgy. Proceedings of Copper 2013: Hydrometallurgy. Ugarte, G. (ed.). Chilean Institute of Mining Engineers, Santiago, Chile. 9 pp. 